Joachim Gessinger Auge \& Ohr 



\section{Joachim Gessinger}

\section{AUGE \& OHR}

Studien zur Erforschung der Sprache am Menschen

$1700-1850$

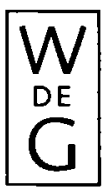

Walter de Gruyter · Berlin · New York 1994 
(@) Gedruckt auf säurefreiem Papier, das die

US-ANSI-Norm über Haltbarkeit erfüllt.

Die Deutsche Bibliothek - CIP-Einbeitsaufnabme

\section{Gessinger, Joachim:}

Auge \& Ohr: Studien zur Erforschung der Sprache am Menschen 1700-1850 / Joachim Gessinger. - Berlin; New York: de Gruyter, 1994

Teilw. zugl.: Berlin, Freie Univ., Habil.-Schr., 1990

ISBN 3-11-013633-3

NE: Gessinger, Joachim: Auge und Ohr

\section{(c) Copyright 1994 by Walter de Gruyter \& Co., D-10785 Berlin}

Dieses Werk einschließlich aller seiner Teile ist urheberrechtlich geschützt. Jede Verwertung außerhalb der engen Grenzen des Urheberrechtsgesetzes ist ohne Zustimmung des Verlages unzulässig und strafbar. Das gilt insbesondere für Vervielfältigungen, Übersetzungen, Mikroverfilmungen und die Einspeicherung und Verarbeitung in elektronischen Systemen.

Printed in Germany

Einbandgestaltung: Christopher Schneider

Satz \& Druck: SOAK GmbH, Hannover

Buchbinderische Verarbeitung: Lüderitz \& Bauer - GmbH, Berlin 